\title{
Optimalisasi Analisis Data Rekam Medis Elektronik Menggunakan Business Intelligence di Rumah Sakit Islam Jakarta Cempaka Putih
}

\author{
Jayanti Aswinasih ${ }^{1}$, Aris Susanto ${ }^{2}$, Hosizah $^{3}$ \\ 1,2,3 Universitas Esa Unggul, Jalan Arjuna Utara no.9 Kebon Jeruk, Jakarta Barat \\ Email: 1'jayantiaswinasih@gmail.com
}

\begin{abstract}
At present, the ease of access to health services has an influence on the number of visits to health facilities, one of which is Jakarta Cempaka Putih Islamic Hospital. An increasing number of visits makes the patient's medical record data also increase and result in big data, known as big data. The number of outpatient visits to the Jakarta Cempaka Putih Islamic Hospital in 2018 has reached 147,232 patients from Jakarta, Bogor, Depok, Tangerang and Bekasi (JABODETABEK). For processing big data, we need a big data processing model using Business Intelligence (BI). This technology can facilitate the processing and presentation of data in a short time and produces an output in the form of a dashboard that can display all information in one window. In order to be quick to making decisions about services, given the lots of visits a fast process is needed so that services are not hampered. This type of research is action research by referring to the business intelligence roadmap. The analysis techniques in this study are multidimensional analysis, exploratory analysis, and trend analysis. The results of the study show are dashboards needed, which are the patient distribution map, age, gender, polyclinic, diagnosis, method of payment, origin of referrals and patient visit trends, and interpret the dashboard into information
\end{abstract}

Keywords: Business Intelligence, Electronic Medical Record

\begin{abstract}
Abstrak
Saat ini, kemudahan akses pelayanan kesehatan memiliki pengaruh terhadap jumlah kunjungan di fasilitas kesehatan, salah satunya adalah Rumah Sakit Islam Jakarta Cempaka Putih. Jumlah Kunjungan yang meningkat menjadikan data rekam medis pasien juga meningkat dan mengakibatkan data besar, yang dikenal dengan big data. Jumlah kunjungan rawat jalan Rumah Sakit Islam Jakarta Cempaka Putih pada tahun 2018 sudah mencapai angka 147.232 pasien yang berasal dari wilayah Jakarta, Bogor, Depok, Tangerang dan Bekasi (JABODETABEK). Untuk pengolahan data yang besar maka diperlukan suatu model pengolahan data besar menggunakan Business Intelligence (BI). Teknologi ini dapat mempermudah pengolahan dan penyajian data dalam waktu singkat serta menghasilkan luaran berupa dashboard yang dapat menampilkan semua informasi dalam satu jendela. Agar cepat dalam pengambilan keputusan terhadap pelayanan, mengingat jumlah kunjungan yang banyak maka diperlukan proses yang cepat agar pelayanan tidak terhambat. Jenis penelitian ini adalah action research dengan mengacu business intelligence roadmap. Teknik analisis dalam penelitian ini adalah multidimensional analysis, exploratory analysis, dan trend analysis. Hasil penelitian menampilkan sejumlah dashboard yang dibutuhkan yakni dashboard peta sebaran pasien, usia, jenis kelamin, poliklinik, diagnosis, cara pembayaran, asal rujukan dan tren kunjungan pasien, serta mengintepretasikan dashboard menjadi sebuah informasi.
\end{abstract}

Kata kunci: Business Intelligence, Rekam Medis Elektronik

\section{PENDAHULUAN}

Instansi kesehatan adalah instansi pelayanan kesehatan yang bertugas memberikan pelayanan kesehatan, pemulihan dan pengobatan masyarakat oleh perseorangan maupun kelompok. Salah satunya adalah rumah sakit. Pertumbuhan instansi pelayanan kesehatan seperti rumah sakit di Indonesia sangat pesat (Bahiyah, Hajar, \& Sejati, 2012). Pertambahan rumah sakit di Indonesia pada tahun 2015 sampai dengan tahun 2016 mencapai sebanyak $133 \mathrm{RS}$ atau mengalami pertumbuhan sebesar 5.3\% (KEMENKES RI, 2016). Hal tersebut disebabkan oleh jumlah kunjungan pasien meningkat. Hal 
ini terjadi seiring perkembangan zaman yang memudahkan cara pembayaran dengan berbagai opsi serta menjamurkan asuransi di Indonesia yang memudahan untuk pasien berobat. Salah satu asuransi yang paling berdampak pada peningkatan pasien adalah BPJS Kesehatan, jumlah kunjungan Rawat Jalan Tingkat Lanjutan (RJTL) tahun 2016 mencapai 49.283.264 kunjungan atau meningkat sebesar $23,79 \%$ bila dibandingkan realisasi pada periode tahun 2015 (BPJS KESEHATAN, 2016).

Pengelolaan data yang besar ini, bertujuan agar rumah sakit dapat mengambil keputusan yang lebih baik untuk peningkatan pelayanan rumah sakit. Maka dari itu Business Intelligence (BI) dapat membantu rumah sakit untuk mengolah data yang berukuran besar dan menghasilkan visualisasi informasi melalui grafik yang bersifat interaktif dan menarik sehingga akan memudahkan dalam membaca informasi, sementara hasil print out (Hardcopy) akan menjadi dokumentasi bagi rumah sakit (Syarli, Tamin, \& Qashlim, 2018). Sehingga dapat membantu rumah sakit dalam pengambilan keputusan serta sekaligus meningkatkan keunggulannya (comptetitive advantage). Selain itu, BI juga dapat membantu rumah sakit dalam menganalisis perubahan trend yang terjadi sehingga dapat membantu rumah sakit dalam menentukan strategi yang diperlukan untuk mengantisipasi perubahan trend tersebut (Arifin, 2014).

Berdasarkan pada observasi awal, RSIJ Cempaka Putih belum pernah memanfaatkan salah satu aplikasi Business Intelligence untuk pengelolaan data rumah sakit yang dapat melakukan analisis terhadap data pasien. Khususnya data yang berasal dari rekam medis elektronik yang dilaksanakan pada pelayanan rawat jalan. Jumlah data pasien yang besar dengan 147.232 pasien pada tahun 2018 yang berdomisili di wilayah JABODETABEK. Rumah Sakit Islam Jakarta Cempaka Putih masih memakai laporan yang berupa dokumen yang berisikan data pasien yang disajikan dalam table sederhana. Dengan laporan yang seperti itu maka laporan tersebut tidak menuntun pembaca pada kesimpulan tertentu. Oleh karena itu rumah sakit memerlukan bentuk pengolahan data yang besar dan dapat dilakukan dengan cara yang ringkas serta tidak memakan waktu yang cukup lama. Pengolahan tersebut dapat dijadikan report ataupun sebagai performance evaluation yang kemudian disajikan dalam visualisasi data berupa dashboard agar pembaca dapat menginterpretasikan data yang ada. Maka dari itu pada penelitian ini, digunakan sebuah aplikasi BI yakni QlikView untuk membantu Rumah Sakit Islam Jakarta Cempaka Putih dalam mengkoordinir data yang dimilikinya.

\section{METODE}

Jenis penelitian ini adalah action research, yang merupakan penelitian upaya pemacahan masalah atau perbaikan yang bersifat reflektif dan kolaboratif. Penelitian ini dilakukan dengan mengacu kepada business intelligence roadmap. Adapun langkah langkah yang dilakukan dilakukan pada business intelligence roadmap (Moss \& Atre, 2003) yang telah dimodifikasi menyesuaikan dengan penelitian sebagai berikut :

a. Fase Justification

Fase justification, melakukan identifikasi masalah dan assessment terhadap kebutuhan rumah sakit,

b. Fase Planning

Fase planning, mengembangkan rencana untuk menghasilkan bagaimana BI akan dikerjakan.

c. Fase Business Analysis

Fase business analysis, melakukan analisis masalah dan peluang untuk mendapatkan pemahaman kebutuhan untuk mencari solusi.

d. Fase Design

Pada tahap ini terdapat desain pemodelan data warehouse yang akan digunakan untuk penyimpanan data dan ETL Design yaitu membangun desain ETL untuk memasukkan data ke dalam data warehouse.

e. Fase Construction

1) Membuat ETL dari data sumber ke OLAP

2) Membuat OLAP agar dapat dibuat dashboard yang telah ditentukan

3) Membuat dashboard yaitu Dashboard peta sebaran pasien rawat jalan RSIJ Cempaka Putih, Dashboarad jumlah pasien rawat jalan RSIJ Cempaka Putih berdasarkan usia, Dashboard jumlah pasien rawat jalan RSIJ Cempaka Putih berdasarkan jenis kelamin, Dashboard jumlah pasien rawat jalan RSIJ Cempaka Putih berdasarkan poliklinik, Dashboard jumah pasien rawat jalan RSIJ Cempaka Putih berdasarkan diagnosis, Dashboard peningkatan jumlah pasien rawat jalan RSIJ Cempaka Putih selama 2018, Dashboard jumlah pasien rawat jalan RSIJ Cempaka Putih berdasarkan cara pembayaran, 


\section{Dashboard jumlah pasien rawat jalan RSIJ Cempaka Putih berdasarkan asal rujukan. \\ f. Fase Data Interpretation}

Mengartikan informasi yang muncul dalam bentuk visual yakni berupa dashboard.

\section{HASIL}

\section{Skema Data Warehouse}

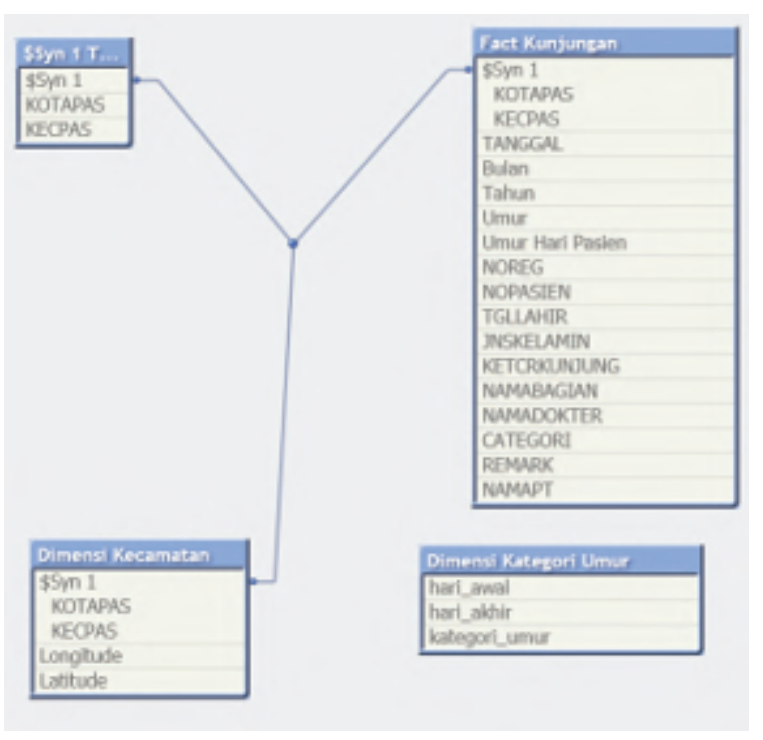

\section{Gambar 1. Skema Data Warehouse}

Berdasarkan gambar diatas dapat diketahui relasi data warehouse kunjungan rawat jalan RSIJ Cempaka Putih. Garis relasi dikarenakan antara 'fact kunjungan' dengan 'dimensi kecamatan' memiliki atribut yang sama hingga saling mengaitkan satu sama lain, hal ini dapat terlihat pada dashboard yang akan digunakan, karena akan terkait satu sama lain. Untuk dimensi 'kategori umur' tidak memiliki relasi dari manapun dibuat hanya untuk mengklasifikasikan umur. Relasi ini dihasilkan dari multidimensional analysis. Kemudian untuk explaratory analysis terdapat pada dashboard jumlah pasien berdasarkan usia, jenis kelamin, poliklinik, diagnosis, cara pembayaran, dan asal rujukan. Trend analysis terdapat pada dashboard peningkatan jumlah pasien rawat jalan RSIJ Cempaka Putih di tahun 2018.

\section{Dimension and Fact Table}

Tabel dibawah ini memuat semua keterangan dan juga jenis data yang terkandung didalam fact kunjungan, dimensi kecamatan, dan dimensi kategori umur.
Tabel 1 Dimension and Fact Table

Dimension dan
Fact Table

2. KECPAS : Berisikan nama kecamatan pasien dengan tipe data varchar

3. TANGGAL : Berisikan tanggal berobat pasien dengan tipe data varchar

4. NOREG : Berisikan kode registrasi pengunjung dengan tipe data integer

5. NOPASIEN : Berisikan kode pasien yang berobat dengan tipe data integer

6. TGLLAHIR : Berisikan tanggal lahir pasien dengan tipe data decimal

7. JNSKELAMIN : Berisikan jenis kelamin pasien dengan tipe data varchar

8. KETCRKUNJUNG : Berisikan cara kunjungan pasien dengan tipe data varchar

9. NAMABAGIAN : Berisikan kode poliklinik RSIJ dengan tipe data string

10. NAMADOKTER : Berisikan nama dokter yang bertugas dipoliklinik dengan tipe data varchar

11. CATEGORI : Berisikan kode diagnosis ICD-10 dengan tipe data string

12. REMARK : Berisikan diagnosis pasien dengan tipe data varchar

13. NAMAPT : Berisikan nama penanggung jawab pembayar pasien yang berobat dengan tipe data varchar

Dimensi

Kecamatan
Menyimpan informasi sistem koordinat geografis yang digunakan untuk menentukan lokasi Kota dan Kecamatan di wilayah Jakarta, Bogor, Depok, Tangerang, Bekasi. Memiliki atribut yang terdiri dari :

1. Longitude : Berisikan garis bujur koordinat lokasi kecamatan pasien dengan tipe data decimal 
2. Latitude : Berisikan garis lintang koordinat lokasi kecamatan pasien dengan tipe data decimal

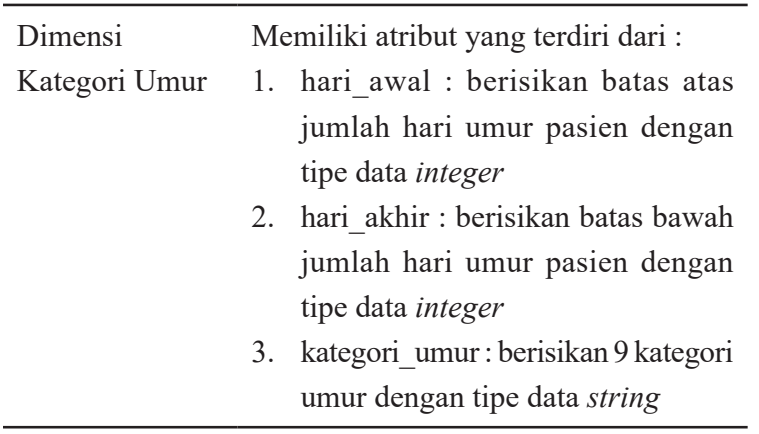

\section{Visualisasi Data}

Dashboard Berdasarkan Peta Rawat Jalan Wilayah DKI Jakarta di Rumah Sakit Islam Jakarta Cempaka Putih Tahun 2018

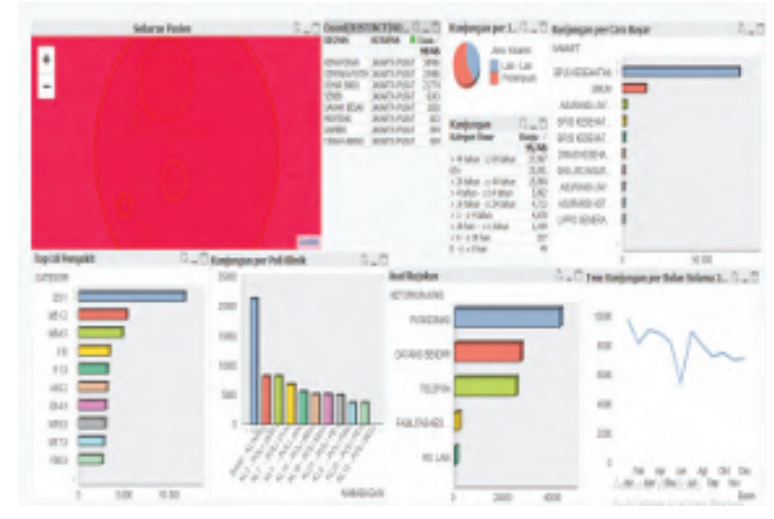

Gambar 2. Dashboard Berdasarkan Peta Rawat Jalan Wilayah DKI Jakarta di Rumah Sakit Islam Jakarta Cempaka Putih Tahun 2018

Pada wilayah DKI Jakarta, pasien terbanyak berasal dari Jakarta Pusat yang memiliki 8 Kecamatan dengan jumlah pasien keseluruhan 95.745 orang. Pasien didominasi dari wilayah Kecamatan Kemayoran sejumlah 38.496 orang. Asal pasien dari Kecamatan Tanah Abang menjadi yang paling sedikit dengan jumlah 509 orang. Pasien laki - laki yang berasal dari wilayah Jakarta Pusat sejumlah 38.881 orang dan pasien perempuan 56.864 orang. Kemudian pasien paling banyak dari kelompok usia $>44$ tahun $-\leq 64$ tahun . Sebagian besar berobat di klinik rehabilitasi medik. Mayoritas penyakit yang diderita adalah I25.1 (atherosclerotic heart disease). Kedatangan pasien ke RSIJ Cempaka Putih sebagian besar asal rujukannya berasal dari puskesmas dengan cara bayar menggunakan BPJS kesehatan.
Dashboard Berdasarkan Peta Rawat Jalan Wilayah Kepulauan Seribu di Rumah Sakit Islam Jakarta Cempaka Putih Tahun 2018

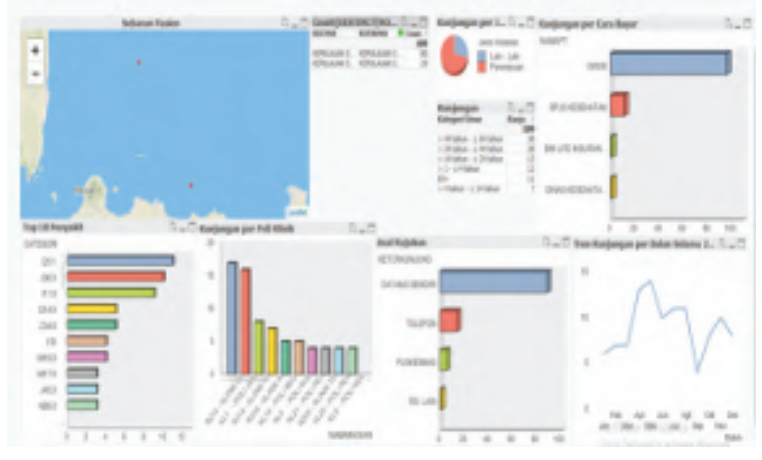

Gambar 3. Dashboard Berdasarkan Peta Rawat Jalan Wilayah Kepulauan Seribu di Rumah Sakit Islam Jakarta Cempaka Putih Tahun 2018

Bagian wilayah Kepulauan Seribu, terdapat pasien dari 2 Kecamatan dengan jumlah pasien keseluruhan 109 orang. Pasien didominasi dari wilayah Kecamatan Kepulauan Seribu Utara sejumlah 80 orang. Asal pasien dari Kecamatan Kepulauan Seribu Selatan menjadi yang paling sedikit dengan jumlah 29 orang. Pasien laki - laki yang berasal dari wilayah Jakarta Selatan sejumlah 31 orang dan pasien perempuan 8 orang. Kemudian pasien paling banyak dari kelompok usia $>44$ tahun $-\leq 64$ tahun. Sebagian besar berobat di klinik dalam. Mayoritas penyakit yang diderita adalah I25.1 (atherosclerotic heart disease). Kedatangan pasien ke RSIJ Cempaka Putih berobat dengan cara kunjungan datang sendiri serta menggunakan cara bayar pasien umum atau pribadi.

Dashboard Berdasarkan Peta Rawat Jalan Wilayah Bogor di Rumah Sakit Islam Jakarta Cempaka Putih Tahun 2018

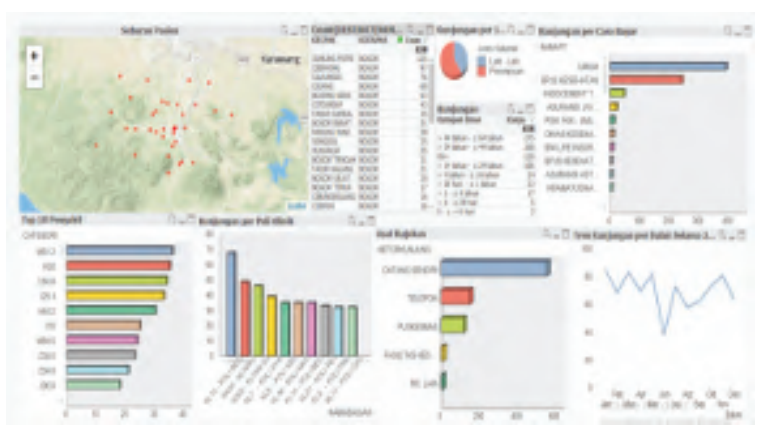

Gambar 4. Dashboard Berdasarkan Peta Rawat Jalan Wilayah Bogor di Rumah Sakit Islam Jakarta Cempaka Putih Tahun 2018 
Sebaran pasien wilayah Bogor, terdiri dari 35 Kecamatan dengan jumlah pasien keseluruhan 838 orang. Pasien didominasi dari wilayah Kecamatan Gunung Putri sejumlah 125 orang. Asal pasien dari Kecamatan Dramaga Selatan menjadi yang paling sedikit dengan jumlah 2 orang. Pasien laki - laki yang berasal dari wilayah Bogor sejumlah 336 orang dan pasien perempuan 502 orang. Kemudian pasien paling banyak dari kelompok usia $>44$ tahun $-\leq 64$ tahun. Sebagian besar berobat di poli bedah. Mayoritas penyakit yang diderita adalah M51.2 (hernia nucleus pulposus). Kedatangan pasien ke RSIJ Cempaka Putih berobat dengan cara kunjungan datang sendiri serta menggunakan cara bayar pasien umum atau pribadi.

Dashboard Berdasarkan Peta Rawat Jalan Wilayah Depok di Rumah Sakit Islam Jakarta Cempaka Putih Tahun 2018

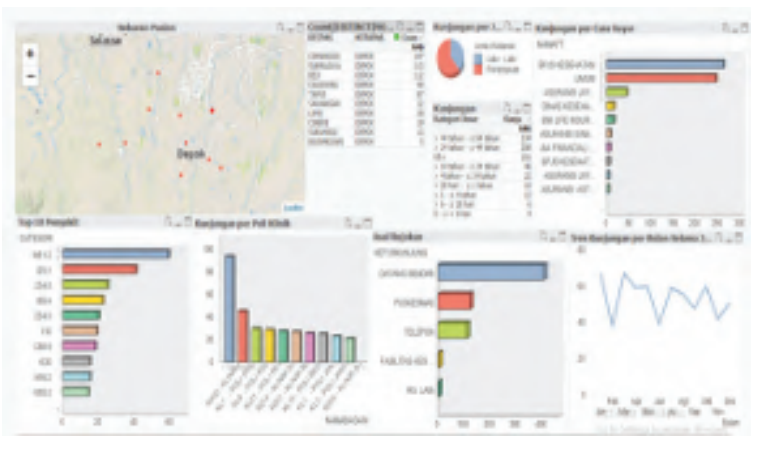

Gambar 5. Dashboard Berdasarkan Peta Rawat Jalan Wilayah Depok di Rumah Sakit Islam Jakarta Cempaka Putih Tahun 2018

Pasien yang berasal dari wilayah Depok, terdiri dari 10 Kecamatan dengan jumlah pasien keseluruhan 646 orang. Pasien didominasi dari wilayah Kecamatan Cimanggis sejumlah 147 orang. Asal pasien dari Kecamatan Bojongsari menjadi yang paling sedikit dengan jumlah 5 orang. Pasien laki - laki yang berasal dari wilayah Depok sejumlah 249 orang dan pasien perempuan 397 orang. Kemudian pasien paling banyak dari kelompok usia $>44$ tahun $-\leq 64$ tahun. Sebagian besar berobat di klinik rehabilitasi medik. Mayoritas penyakit yang diderita adalah M51.2 (hernia nucleus pulposus). Kedatangan pasien ke RSIJ Cempaka Putih berobat dengan cara kunjungan datang sendiri serta menggunakan BPJS Kesehatan sebagai pembayarannya..

Dashboard Berdasarkan Peta Rawat Jalan Wilayah Tangerang di Rumah Sakit Islam Jakarta Cempaka Putih Tahun 2018

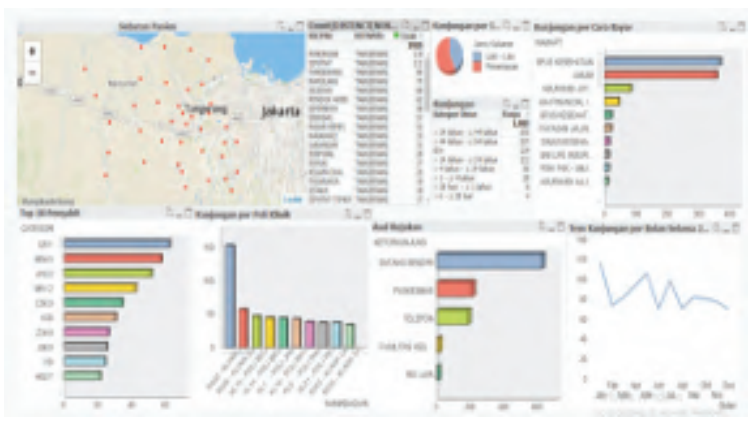

Gambar 6. Dashboard Berdasarkan Peta Rawat Jalan Wilayah Tangerang di Rumah Sakit Islam Jakarta Cempaka Putih Tahun 2018

Pada wilayah Tangerang, terdiri dari 38 Kecamatan dengan jumlah pasien keseluruhan 1.025 orang. Pasien didominasi dari wilayah Kecamatan Panongan sejumlah 119 orang. Asal pasien dari Kecamatan Jatiuwung menjadi yang paling sedikit dengan jumlah 3 orang. Pasien laki - laki yang berasal dari wilayah Tangerang sejumlah 441 orang dan pasien perempuan 584 orang. Kemudian pasien paling banyak dari kelompok usia $>24$ tahun $-\leq 44$ tahun. Sebagian besar berobat di klinik rehabilitasi medik. Mayoritas penyakit yang diderita adalah I25.1 (atherosclerotic heart disease). Kedatangan pasien ke RSIJ Cempaka Putih berobat dengan cara kunjungan datang sendiri serta menggunakan BPJS Kesehatan sebagai pembayarannya.

Dashboard Berdasarkan Peta Rawat Jalan Wilayah Bekasi di Rumah Sakit Islam Jakarta Cempaka Putih Tahun 2018

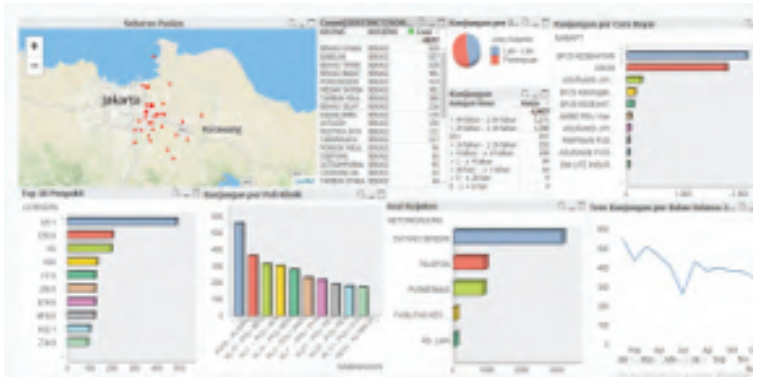

Gambar 7. Dashboard Berdasarkan Peta Rawat Jalan Wilayah Bekasi di Rumah Sakit Islam Jakarta Cempaka Putih Tahun 2018

Selanjutnya wilayah Bekasi, terdiri dari 29 Kecamatan dengan jumlah pasien keseluruhan 4.977 orang. Pasien didominasi dari wilayah Kecamatan Bekasi Utara sejumlah 929 orang. Asal pasien dari Kecamatan Kedungwaringin menjadi yang paling sedikit dengan jumlah 1 orang. Pasien laki-laki yang berasal dari wilayah Bekasi sejumlah 2.324 orang 
dan pasien perempuan 2.653 orang. Kemudian pasien paling banyak dari kelompok usia $>44$ tahun $-\leq 64$ tahun. Sebagian besar berobat di klinik rehabilitasi medik. Mayoritas penyakit yang diderita adalah I25.1 (atherosclerotic heart disease). Kedatangan pasien RSIJ Cempaka Putih berobat dengan cara kunjungan datang sendiri serta menggunakan BPJS Kesehatan sebagai pembayarannya.

\section{PEMBAHASAN}

Dashboard peta dapat dilihat informasinya tentang bagaimana pola sebaran pasien pada wilayah DKI Jakarta. Hal ini juga dapat diteliti lebih lanjut untuk menganalisis faktor yang mempengaruhi pemilihan RSIJ Cempaka Putih sebagai tempat berobat, misalnya faktor aksesibilitas, pelayanan kesehatan, biaya pengobatan, atau faktor fasilitas kesehatannya. Selain itu dari dashboard peta ini juga dapat diketahui darimana wilayah yang paling banyak pasien berobat agar dapat dianalisis lebih lanjut terkait permasalahaan penyakit dan faktor resiko lainnya di daerah tersebut.

Dashboard kategori umur di sesuaikan dengan Formulir Data Keadaan Morbiditas Pasien Rawat Jalan Rumah Sakit RL 4b, agar kedepannya dapat digunakan sebagai laporan ke pihak Kementrian Kesehatan. Dashbord jenis kelamin ini dapat digunakan sebagai bahan laporan internal seperti key performance indicator dan eksternal rumah sakit seperti laporan Morbiditas Pasien Rawat Jalan Rumah Sakit RL 4b.

Menurut Efraim Turban (2011) salah satu lapisan informasi pada dashboard adalah monitoring (pemantauan), dashboard ini dapat digunakan untuk memantau bagaimana kinerja masing - masing poliklinik yang ada di RSIJ Cempaka Putih. Besaran jumlah pasien yang berobat tiap harinya menjadi salah satu hal yang dapat dipertimbangkan, maka dapat diketahui apakah angka besaran pasien berobat dapat mempengaruhi pelayanan kesehatan. Seperti yang dijelaskan oleh Nurul Bahiyah (2012) dalam penelitiannya bahwa keuntungan yang didapat rumah sakit jika mengimplementasikan business intelligence antara lain peningkatan kinerja, peforma organisasi, dan peningkatan pelayanan kesehatan.

Dashboard diagnosis ini dapat digunakan untuk mengetahui 10 penyakit terbesar rumah sakit. Harapannya agar dapat dilaporkan kepada Dinas Kesehatan dan Kementerian Kesehatan dan dapat di analisis apa penyebab dan faktor resikonya. Dashboard diagnosis juga dapat memantau pengkodean yang telah dilakukan oleh koder, apakah kode tersebut telah sesuai atau tidak dengan aturan yang telah ditentukan oleh Tim Nasional Casemix Center.

Dashboard Peningkatan Jumlah Pasien ini berguna untuk memantau jumlah pasien agar pihak rumah sakit dapat mengidentifikasi tindakan apa yang harus diambil jika terjadi hal - hal yang menyebabkan adanya penurunan jumlah pasien yang berobat. Selain itu, pada dashboard peningkatan jumlah pasien, pihak rumah sakit juga dapat mengestimasi volume jumlah pasien kedepannya agar dapat merencanakan program pelayanan yang optimal.

Dashborad cara bayar ini juga dapat menilai besaran pasien yang membayar dengan dana pribadi atau menggunakan asuransi kesehatan. Dashbord asal rujukan ini dapat digunakan untuk mengetahui besaran pasien yang memakai jenjang rujukan dari Fasilitas Kesehatan Tingkat Pertama (FKTP) dan juga dapat mengetahui besaran pasien dari cara kunjung lainnya.

\section{SIMPULAN}

Gambaran pasien rawat jalan RSIJ Cempaka Putih ditampilkan dalam satu jendela, dengan satu dashboard dapat menampilkan banyak informasi. Dashboard peta sebaran dapat menampilkan asal pasien terbanyak dari Jakarta Pusat sebanyak 95.743 orang, jenis kelamin pasien terbanyak adalah perempuan sebanyak 56.864 (59,4\%) orang, sebagian besar pasien berusia antara $>44$ tahun sampai $\leq 64$ tahun sebanyak 37.967 orang, pasien paling banyak berobat di klinik rehabilitasi medik sebanyak 21.349 orang, mayoritas penyakit yang diderita pasien adalah atherosclerotic heart disease (I25.1) dengan jumlah 11.573 orang, sebagian besar asal rujukan pasien dari puskesmas berjumlah 42.526 orang dengan cara bayar menggunakan BPJS kesehatan.

\section{UCAPAN TERIMA KASIH}

Ucapan terima kasih yang pertama peneliti haturkan setulus - tulusnya kepada pembimbing yang membantu, menginspirasi, dan memotivasi untuk belajar lebih giat mengenai ilmu business intellignece. Kedua, untuk pihak Program Studi Manajemen Informasi Kesehatan Universitas Esa Unggul. 


\section{DAFTAR PUSTAKA}

Akbar, R., Darman, R., Namora, J., \& Ardewati, N. (2018). Implementasi Business Intelligence Menentukan Daerah Rawan Gempa Bumi di Indonesia dengan Fitur Geolokasi, (June). Retrieved from : https://doi.org/10.26418/ jp.v4i1.25518

Akbar, R., Soniawan, A., Dinur, R., Adrian, J., Azim, R., Zikri, A., ... Pendahuluan, I. (2017). Implementasi Business Intelligence untuk Menganalisis Data Persalinan Anak di Klinik Ani Padang dengan Menggunakan Aplikasi Tableau Public, 2(1), 20-24. Retrieved from : https://www.researchgate. net/publication/318118425_Implementasi_ Business_Intelligence_untuk_Menganalisis_ Data_Persalinan_Añak_di_Klinik_Ani_Padang_dengan_Menggunakan_Aplikasi_Tableau_Public

Amatayakul, M. K. (2013). Electronic Health Record (fifth). Chicago: American Health Information Management Association.

Arifin, M. (2014). Business Intelligence Untuk Prediksi Customer Churn Telekomunikasi, 279-286. Retrieved from : https://jurnal.umk. ac.id/index.php/SNA/article/view/156

Bahiyah, N., Hajar, R., \& Sejati, P. (2012). Business Intelligence Untuk Instansi Pelayanan Kesehatan: Manfaat Dan Peluangnya Di Indonesia, (September). Retrieved from : https://journal.uii.ac.id/snimed/article/ view/4093

BPJS KESEHATAN. (2016). Ringkasan Eksekutif Laporan Pengelolaan Program dan Laporan Keuangan Jaminan Sosial Kesehatan. Retrieved from : https://bpjs-kesehatan.go.id/ BPJS/index.php/arsip/detail/951

Gaardboe, R., Sandalgaard, N., \& Nyvang, T. (2017). An assessment of business intelligence in public hospitals, 5(4), 5-18. Retrieved from : https://doi.org/10.12821/ijispm050401

Handiwidjojo, W. (2009). Rekam medis elektronik, 02, 36-41. Retrieved from : https://ti.ukdw. ac.id/ojs/index.php/eksis/article/view/383

K, Huffman, E. (1994). Health Information Management. (J. Cofer, Ed.) (tenth). Berwyn: Physicians Record Company.
Kao, H., Yu, M., Masud, M., Wu, W., Chen, L., \& Wu, Y. J. (2016). Computers in Human Behavior Design and evaluation of hospitalbased business intelligence system ( HBIS ): A foundation for design science research methodology. Computers in Human Behavior, 62, 495-505. Retrieved from : https://doi. org/10.1016/j.chb.2016.04.021

KEMENKES RI. (2004). Undang - Undang Republik Indonesia Nomor 29 Tahun 2004 Tentang Praktik Kedokteran. Retrieved from : https:// www.google.com/url?sa=t\&source $=$ web\& $\mathrm{rct}=\mathrm{j} \& u r l=\mathrm{http}: / /$ ditjenpp.kemenkumham. go.id/a r si p/ln/2004/u u 292004 . df\&ved=2ahUKEwjhwNjfoNPkAhWFOI8 KHdtMDvcQFjAAegQIAxAB\&usg=AOvV aw2mewaPKKrKcELYxTN16bHs

KEMENKES RI. (2008). Peraturan Menteri Kesehatan Republik Indonesia No. 269/ MENKES/PER/III/2008 Tentang Rekam Medis. Retrieved from : http://buk. depkes.go.id/index.php?option $=$ com docman\&task $=$ doc details \&gid $=35 \& \mathrm{It}$ emid=142\%5Cnbuk.depkes.go.id/index. php?option $=$ com_docman\&task $=$ doc download\&gid=35\&Itemid $=112$

KEMENKES RI. (2011). Petunjuk Teknis Sistem Informasi Rumah sakit. Retrieved from : https:// www.google.com/url?sa=t\&source=web\&r $\mathrm{ct}=\mathrm{j} \& u r l=h t t p: / / y a n k e s . k e m k e s . g o . i d /$ assets/ downloads/Juknis\%2520SIRS\%25202011. pdf\&ved=2ahUKEwis5qzUotPkAhULso8K HeVID-UQFjAAegQIARAB\&usg=AOvVa w1e6qqVpr80dAAWewgMbP3P

KEMENKES RI. (2013). CODE CREEP, 1-9. Retrieved from : https://www.google.com/ amp/s/dokumen.tips/amp/documents/codecreep.html

KEMENKES RI. (2016). Laporan Akuntabilitas Kinerja Instansi Pemerintah. Retrieved from : https://www.google.com/url?sa $=$ t\&source $=$ w eb\&rct=j\&url=http://depkes.go.id/resources/ download/LAKIP2017/6\%2520LKj\%2520E s\%25202\%25202016/1\%2520LKj\%2520Es 2\%2520Yankes/LAKIP\%2520YANKES\%2 520PRIMER\%25202016.pdf\&ved=2ahUK EwjZ4OTal9PkAhVkmuYKHb0oA2EQFjA AegQIAxAB\&usg=AOvVaw37mDMRHln yjwz5QgiB-cZk 
Mettler, T., \& Vimarlund, V. (2009). Understanding Business Intelligence In The Context of Healthcare, 15(3), 254-264. Retrieved from : https://doi. org/10.1177/1460458209337446

Moss, L. T., \& Atre, S. (2003). Business Intelligence Roadmap : The Complete Project Lifecycle for Decision Support Application. Retrieved from : https://books.google.co.id/books?id= HSeE7rOXKsUC\&pg=PR2\&dq $=$ Moss + LT ,+Atre + S.+Business + Intelligence + Roadma p $\%$ E2\% $\% 0 \%$ AF $:+$ The + Complete + Project + Lifecycle + for + Decision + Support + Applica tion. $+2003 \&$ hl $=$ en $\&$ sa $=$ X\&ved $=0$ ahUKEw iK_PmQo9PkAhUMUI8KHeYpAH4Q6wEII DAA\# $\mathrm{v}=$ onepage $\& \mathrm{q}=\mathrm{Moss} \% 20 \mathrm{LT} \% 2 \mathrm{C} \% 20$ Atre\%20S.\%20Business\%20Intelligence $\% 20$ Roadmap\%E2\%80\%AF\%3A\%20The\%20 Complete $\% 20$ Project $\% 20$ Lifecycle $\% 20$ for $\% 20 \mathrm{Dec}$ is ion $\% 20 \mathrm{Support} \% 20$ Application. $\% 202003 \& \mathrm{f}=$ false

NPGeoMap. (2019). QlikView and Qlik Sense map Extension. Retrieved from : http://www. npgeomap.com/index.php/en/
Prajena, G., Yesmaya, V., Darmawan, D., \& Sudarma, H. (2014). Arsitektur Business Intelligence Berorientasi User, 157-163. Retrieved from: https://journal.unesa.ac.id/index.php/jieet/ article/view/2615

QlikView. (2019). QlikView. Retrieved from : https:// www.qlik.com/us/products/qlik-geoanalytics

Saputra, H. (n.d.). Pembangunan Data Warehouse Pada Institusi Balai Pengkajian Teknologi Pertanian ( BPTP ) Jawa Barat. Retrieved from : https://elib.unikom.ac.id/gdl.php?mo $\mathrm{d}=$ browse\&op=read\&id=jbptunikompp-gdlhengkysapu-33649

Syarli, Tamin, R., \& Qashlim,A. (2018). Perancangan Business Intelligence System Pada Gudang Farmasi Dinas Kesehatan Kabupaten Mamasa, 1(1). Retrieved from : http://journal.unhas. ac.id/index.php/juteks/article/view/4274

Turban, E., Sharda, R., \& Delen, D. (2011). Decision Support and Business Intelligence System (9th ed.). Pearson.

Vercellis, C. (2009). Business Intelligence (1st ed.). John Wiley \& Sons Ltd. 